\title{
Jack Hammer
}

from $A$ ND $A_{\text {fFter }}$ ManY $A$

Summer Dies the DuCK

I have a friend who wrote a book.

Yes.

Writing is often self-destructive, especially if your stuff is filled

with finely-wrought irony.

They say that New Orleans has many

balconies and gates

of finely-wrought irony.

That is not what I'm talking about, at all.

I put two poems

of equal length

side by side

and spent an hour

trying to decide

which was the better.

Imagine the shame

of having to choose

this one. 